\title{
Em Busca dos Dragões: a Idade Média no Brasil
}

Searching for Dragons: the Middle Ages in Brazil

Nadia R. Altschul ${ }^{1}$ Lukas Gabriel Grzybowski 


\section{O que é medievalismo pós-colonial?}

Em sua forma mais reconhecida, o medievalismo é o reaproveitamento de elementos considerados “medievais" em qualquer formato e época após o fim da Idade Média histórica. Essa cronologia histórica está associada aos anos 5001500 da era cristã e cobre desde a queda de Roma até o Renascimento. Nesta primeira posição teórica da disciplina, no entanto, os estudos do medievalismo pressupõem, por um lado, o fim da Idade Média e, por outro, um reuso consciente de que esta Idade Média constitui-se num período do passado, um período que deveria ter terminado para que o medievalismo propriamente dito pudesse começar. Leslie Workman estabeleceu essa separação no primeiro volume da revista Studies in Medievalism (SIM), onde observou que "o medievalismo só poderia começar, não simplesmente quando a Idade Média tivesse acabado, quando quer que tenha sido, mas quando a Idade Média foi percebida como algo no passado, algo que era necessário reviver ou desejável imitar" (WORKMAN, 1979, p. 1, tradução nossa). ${ }^{3}$

Essa separação em relação a um tempo que se encerrou e sua percepção como ocorrida no passado não é especialmente problemática para os centros hegemônicos de conhecimento. Para os centros hegemônicos, sua própria Idade Média é uma época histórica que já acabou e que está, em seu próprio imaginário, cuidadosamente colocada além da realidade cotidiana. Mas essa mesma posição teórica acerca do final do período medieval cria dificuldades nas áreas pós-coloniais ou no chamado mundo subdesenvolvido. As áreas póscoloniais são consideradas como carentes de um verdadeiro passado medieval europeu e, ao mesmo tempo, são em sua maioria vistas como sociedades atrasadas, sociedades anacrônicas onde continuam os modos de vida medievais que estão fora de sincronia com o presente. Como outros países do sul global, o Brasil sofreria de ambos os problemas, tanto pela falta de uma Idade Média própria que lhe permitisse estudar o "após" de uma autêntica era medieval, quanto pelo fato de grande parte de sua extensão continuar a ser considerada por muitos como uma sociedade ultrapassada que ainda vive dentro de uma certa Idade Média. Nessas condições, então, o que significa estudar “a Idade Média" e o medievalismo no Brasil?

Os estudos pós-coloniais podem nos ajudar a reconhecer as razões e diretrizes de tal projeto. Diante da noção mais comum nos estudos do medievalismo (de que há uma Idade Média histórica que é reutilizada e volta a se difundir após 1500), uma perspectiva pós-colonial sobre a disciplina e um compromisso 
explícito com localidades fora da Europa nos mostram um panorama distinto. Ao contrário da posição comum acima mencionada, estas localidades permitemnos perceber mais claramente que, antes que um reaproveitamento da "Idade Média” possa ocorrer, uma ideia prévia do que é a "Idade Média” deve ser criada para o seu consumo e sua nova difusão.

Como exemplo, podemos citar dragões. Não há dúvida de que os dragões jamais existiram, nem na época medieval ou antes dela, e que, como criaturas do universo fantástico, encontram-se tanto fora da Europa como em tempos anteriores à Idade Média, como no caso da China. É também notável, no entanto, que hoje em áreas cultural e economicamente hegemônicas os dragões se tornaram um elemento frequente em cenários "medievais", não aparecendo menos que castelos, armaduras e monarcas. O medievalismo como disciplina, então, não é sobre se os dragões existiam na Idade Média real ou cronológica. O que o medievalismo aborda é o fato de que hoje os dragões se tornaram elementos comuns da ideia de "medieval" nas produções culturais do Atlântico Norte. Ressalte-se que os dragões não foram os elementos primários da ideia do medieval no século XIX, mas pode-se dizer que eles o são no medievalismo do século XXI no Atlântico Norte. O que podemos aprender com esses “dragões”, então, é que os elementos associados ao medievalismo mudam com o tempo e que devem ser formulados como "medievais" antes que possam ser difundidos efetivamente em um lugar e tempo específicos. Da mesma forma, este exemplo nos permite apontar que a necessidade de que um componente seja inventado como medieval antes que se possa usá-lo como medieval também se aplica a centros hegemônicos e a geografias que supostamente tiveram sua própria e verdadeira Idade Média. Em centros e geografias com passado medieval histórico, esses elementos não devem ser considerados ou tomados como mais "autênticos" ou menos inventados do que nas periferias. Em outras palavras, qualquer lugar e qualquer época terão que ter formulado e difundido seus próprios "dragões"-seus próprios elementos do que é "medieval" e com eles suas próprias versões e seus próprios reaproveitamentos locais do medievalismo. Um estudo de quais são as versões brasileiras de "o medieval" e, portanto, de quais são suas próprias formas de medievalismo, é o diálogo que começa a se realizar através desse dossiê.

Sendo um novo campo de estudos, este dossiê também mostra a tensão que existe entre as obras que acompanham os estudos do medievalismo tal como são definidos em suas versões anglófonas, e a compreensão pós-colonial mais ampla do campo no qual o Brasil, para seguir nossa própria metáfora, encontrará 
seus próprios “dragões". Essas tensões e as dificuldades que o conhecimento hegemônico cria nas tradições pós-coloniais de conhecimento não são novas. Por exemplo, após um encontro em São Paulo em 2003, organizado por colegas europeus francófonos com o objetivo de aprender como era a Idade Média do "além-mar" da América do Sul, o professor francês Joseph Morsel se mostrou decepcionado devido ao caráter imitativo dos estudos medievais na América Latina. Ele observou que esses estudos usaram a mesma construção cronológica, os mesmos métodos e as mesmas metodologias possíveis que na Europa. Morsel reclama que, embora os ibero-americanos olhem para a Idade Média "do equador", eles claramente não a vêem de forma diferente dos europeus ou oferecem algo que os europeus não tenham visto (MORSEL, 2003, p. 3). Ao contrário, os ibero-americanos teriam simplesmente importado as diretivas europeias para seus próprios estudos. O que, então, o Brasil pode oferecer se for apenas um derivado deslocado fazendo o mesmo e da mesma forma que os centros hegemônicos?

Como muitos neste dossiê reconheceram, uma boa resposta é o medievalismo. O medievalismo é uma forma produtiva e intelectualmente estimulante de lidar precisamente com o uso local do "medieval" e das funções que o medieval tenha exercido em um cenário específico como o Brasil. Porque o medievalismo está interessado no lugar e na época em que o medieval é difundido, seja na Austrália, França ou Brasil: que função ele teve? Por que foi usado? Com que efeitos? Quais foram as razões para inventar um determinado elemento como "medieval" em uma época e lugar específicos?

Estipulemos também claramente que os estudos de caráter derivativo não são um problema exclusivo do "equador" e são encontrados em universidades europeias, marcadas por um nepotismo evidente, ou em universidades do Atlântico Norte, onde a falta de financiamento suprime a maioria dos projetos de pesquisa mais inovadores. Há também uma certa facilidade em exigir desde os centros de produção intelectual que as periferias acadêmicas "nos surpreendam" e "nos deem" algo novo e desconhecido. Em sua forma mais crua, essas expectativas são transformadas em uma forma de extrativismo, em que geografias menos familiares fornecem uma "renovação" e novos materiais para localidades hegemônicas, estas já talvez sem brilho ou absortas em suas rotinas, mas ainda exercendo autoridade. Junto com o desejo de novidade, uma questão semelhante é que é muito fácil saber pouco ou nada sobre o que acontece e é feito nas periferias, exceto quando esses trabalhos se enquadram em contextos disciplinares reconhecíveis. Há, portanto, uma linha tênue que 
separa o fornecimento de produções acadêmicas que são "iguais"-e, portanto, imitativas e desinteressantes-e fornecer inovações acadêmicas que são demasiado "nicho" em um contexto disciplinar regido principalmente pela academia de língua inglesa.

\section{A favor do neomedievalismo}

Uma área em que os praticantes brasileiros estão se posicionando para mudar é a “controvérsia” entre o medievalismo e o neomedievalismo. O que hoje é conhecido como medievalismo no Atlântico Norte poderia facilmente ter sido conhecido como estudos do neomedievalismo. Para os estudiosos brasileiros, a questão do neomedievalismo ressurge porque “neo” é a terminologia mais óbvia e direta. Se essa terminologia tivesse sido incorporada nos centros hegemônicos, aqueles que estudam a Idade Média histórica fariam o chamado medievalismosentido que continua a ser corrente na América Latina-enquanto aqueles que estudam as reapropriações posteriores fariam o neomedievalismo. Se essa seria uma solução possível, por que falamos em medievalismo e não em neomedievalismo no campo anglófono e seus derivados?

Um dos motivos é que seu fundador nos Estados Unidos, Leslie Workman, chamou a disciplina de medievalismo e só fazia distinções entre os estudos medievais e o medievalismo, sem mencionar o "neo" e às vezes sem reconhecer abertamente a correlação entre medievalismo e classicismo. Assim, em entrevista no livro em sua homenagem, publicado na década de 1990, Workman associa os estudos clássicos aos estudos medievais, mas não identifica a existência do classicismo como um processo de criação do passado grecoromano, paralelo ao medievalismo como um processo de criação da Idade Média (UTZ, 1998, p. 446-447). Já em relação ao Brasil e a possibilidade de se optar pelo termo neomedievalismo na contramão de Workman, Clínio Amaral menciona em entrevista ao grupo de pesquisa Linhas, que sua importância no Brasil se deve ao uso dado em Travels in Hyperreality de Umberto Eco, uma figura fundadora da disciplina e cujo renome e reconhecimento superam Workman, principalmente no Brasil, onde a historiografia está mais voltada à Europa (particularmente à França) do que aos Estados Unidos. Disciplina em início de incorporação e, se necessário, contando com uma figura fundadora alternativa como Eco, o Brasil é terreno fértil para o restabelecimento do termo neomedievalismo como equivalente ao uso corrente encontrado na academia de língua inglesa e seus seguidores. 
Sejamos também claros que na academia de língua inglesa o senso de medievalismo e neomedievalismo não é hermético nem desprovido de fissuras. Dentro dessa academia seria possível usar o termo medievalismo igualmente para se referir a "estudos medievais", tanto por ser um termo generalizado quanto pelo fato de os estudos medievais também ocorrerem após a Idade Média histórica. Por outro lado, diante das investidas de uma cultura popular que mistura e reinventa radicalmente o significado de "medieval", a academia anglófona têm se esforçado para manter o termo medievalismo intacto, referindo-se a produções que mantêm vínculos com “a verdadeira Idade Média”, enquanto ela, finalmente, inclina-se ao uso do termo neomedievalismo para aquelas produções mais desligadas do período histórico e que mostram um distanciamento lúdico em relação a este passado. Para quem se apegava ao uso original institucionalizado por Workman, o medievalismo entraria em diálogo com a Idade Média cronológica e seus elementos históricos, enquanto o neomedievalismo mostraria maior desconexão com estes, vinculando-se com produções que apenas produzem o "sentimento" do medieval.

Uma forma de esclarecer os limites e possibilidades das terminologias medievalismo e neomedievalismo é uma comparação com os termos muito mais familiares e comuns de classicismo e neoclassicismo. Como é bem conhecido das histórias culturais da literatura e da arte, o classicismo foi uma tentativa erudita de recuperação de traços culturais durante o chamado Renascimento, que seus praticantes associaram ao passado greco-romano e consideraram esquecidos após a queda de Roma: foi um renascimento, um ressurgimento da antiguidade clássica. Este sentido constitui um bom paralelo em relação ao chamado “Medieval Revival”, como o medievalismo foi chamado quando pela primeira vez se tornou objeto de estudo das Ilhas Britânicas: um movimento de retorno aos valores, estéticas e modos de vida do passado, associados à Idade Média histórica e que consideravam-se perdidos em meio à era industrial. Isso se torna visível, por exemplo, na restauração da cavalaria ou no retorno ao catolicismo no chamado Movimento de Oxford. Devemos já notar que em contraste com o "Medieval Revival” ou, se quisermos, o "renascimento medieval" das Ilhas Britânicas, os primórdios do “medievalismo" na América espanhola e portuguesa não apresentam um renascimento ou um desejo nostálgico de reviver o passado, mas uma forte rejeição dos elementos que associavam-se com o medieval. $\mathrm{Na}$ Ibero-América, então, as primeiras mobilizações foram desde o início formas do “neomedieval” no seu sentido de apropriação a-histórica: não ressurgimento de tempos acabados, mas mobilizações politicamente motivadas com pouco 
ou nenhum interesse na autenticidade de um passado histórico (ALTSCHUL, 2020). Mencionemos novamente que o termo usado para o renascimento da antiguidade clássica é classicismo, enquanto as reutilizações e reproduções do período clássico após o século XVIII são conhecidas como neoclassicismo. Em contraste com o Renascimento ou o classicismo, o neoclassicismo não busca a recuperação ou ressurgimento da antiguidade clássica, mas, em vez disso, volta a difundir, por suas próprias razões e motivos, certos elementos que permaneceram filiados à antiguidade: leis rígidas nas produções culturais, arranjos considerados racionais, estruturas imponentes, colunas e mármores em seus edifícios. As linhas gerais do neoclassicismo podem então fornecer uma analogia com o neomedievalismo: um uso posterior e remoto de um suposto revival original e que manipula e implanta elementos quase estereotipados que permaneceram afiliados a uma ideia da Antiguidade Clássica ou da Idade Média. Além do auxílio que essas analogias com respeito ao confuso termo medievalismo podem nos oferecer, o que é evidente é que há boas, ou talvez melhores razões para associar nosso campo ao termo neomedievalismo do que continuar com o uso já estabelecido, mas confuso, que vem até nós hoje através da academia de língua inglesa. Nesse sentido, é instrutivo observar que Workman, como vimos, não tinha em mente o conceito de neoclassicismo ou de "neo" como um equivalente que o teria ajudado a avançar do neoclassicismo ao neomedievalismo. Uma hipótese nesse sentido é que o neoclassicismo (como o barroco) não foi uma categoria primária na disciplina histórica, na qual se formou, como o é na história literária e na história da arte. Por outro lado, essa ausência do neoclassicismo como categoria cultural que pudesse funcionar como intermediária foi exacerbada pela importância central dada ao ditado de Lord Acton em 1859, e que se reproduz até hoje nos volumes de Studies in Medievalism. Como as epígrafes tornam explícito:

Dois grandes princípios dividem o mundo e disputam o domínio, a antiguidade e a idade média. Estas são as duas civilizações que nos precederam, os dois elementos que compõem o nosso. Todas as questões políticas e também religiosas se reduzem praticamente a isso. Este é o grande dualismo que permeia nossa sociedade (DALBERG-ACTON, 2010, p. 9, tradução nossa) ${ }^{4}$

Em suas origens, o uso dessa posição maniqueísta de Lord Acton foi uma exigência na busca por reconhecimento e aceitação de uma nova disciplina, e a elevação da Idade Média ao nível de uma Antiguidade de cuja importância 
ninguém duvidava. Mas o "medievalismo", como o tratamos aqui, ficou refém nessa divisão dicotômica necessária em seus primórdios. A divisão categórica que continua nas epígrafes do SIM parece ter sido estabelecida como uma categoria elementar, levando Richard Utz e Tom Shippey, por exemplo, no volume em homenagem a Workman, a elogiar a frase de Acton por sua "abrangência definitiva" e a identificar uma "cisão clássico/medieval" (UTZ; SHIPPEY, 1998, p. 5, 10, tradução nossa $)^{5}$. Essa cisão é problemática: ela estabelece apenas dois canais únicos que negam na prática que outras civilizações como o Islã ou o mundo pré-colombiano tenham contribuído com elementos essenciais para "nossa" civilização. Também, em relação ao tema que nos interessa agora, estabelece uma progressão temporal em que o medievalismo chega com a era romântica. ${ }^{6}$ Um caso instrutivo dessa progressão e dualidade fundamental pode ser visto na explicação de William Calin no mesmo volume em homenagem a Workman. Ali, Calin explica que o medievalismo é "igual" ao classicismo, embora "seu oposto" e "seu contrapeso", mas com a diferença temporal de que o classicismo foi uma invenção do início da modernidade, enquanto o medievalismo é uma invenção dos séculos mais recentes (CALIN, 1998, p. 451, tradução nossa).

Mas são essas questões terminológicas mesquinhas e, em última análise, ninharias? A incorporação de uma nova disciplina é precisamente um daqueles momentos que podem se tornar oportunidades perdidas e posições imitativas e, portanto, decepcionantes do que poderia ter sido uma posição intelectual própria e, portanto, verdadeiramente inovadora. Voltando ao dossiê, então, e como vários de seus ensaios observam, não há razão para "transferir" as perspectivas da língua inglesa para novos territórios como o Brasil. Ao contrário, um verdadeiro desvio pós-colonial pode deslocar a disciplina para fora de seus canais usuais e oferecer uma transformação em como ela se entende; pode conter uma transferência que não é imitativa, mas segura em suas diferenças e perspectivas. $O$ que se propõe aqui, sob o signo de uma transferência pós-colonial, é que a abertura dessa disciplina no Brasil possa ser pautada pelo neomedievalismo como termo mais preciso e adequado para examinar as invenções e os reaproveitamentos de elementos daquilo que em nossos próprios espaços e trajetórias têm sido associado ao "medieval".

**

Por sua singularidade, o Brasil colocou desde cedo os pesquisadores interessados no passado medieval diante de um complexo dilema: afirmar a necessidade do estudo de uma Idade Média histórica em um país que não a havia 
experimentado; e, ao mesmo tempo, construir um discurso que equilibrasse a conexão com o passado medieval português sem perder a formação de uma identidade própria nos horizontes dos debates acadêmicos. Ao leitor desavisado, tal problemática parece longínqua, assentada sobre os momentos fundadores da disciplina histórica no território brasileiro. Todavia, um mero olhar para as discussões levantadas em torno da proposta da Base Nacional Curricular Comum, que excluía do conjunto de temas de ensino obrigatório da disciplina histórica aqueles referentes à Idade Média-entre outros, vale lembrar. O tom geral das críticas levantadas por especialistas do medievo nas diversas manifestações de desagravo à proposta do governo federal incluía sistematicamente a ideia de que o passado brasileiro se estenderia, de uma forma ou outra, sobre a Idade Média europeia através da colonização portuguesa. Seríamos, portanto, também medievais, no sentido de herdeiros de uma tradição transferida pelos colonizadores, a qual não somente justifica ainda o investimento em pesquisa na área, mas também a sua presença nos currículos de ensino obrigatório. Como tal noção persistente se formou na academia brasileira ao início do século XX é o tema do artigo que abre o dossiê aqui apresentado. Nele, Renan Birro aborda o tema dos colonialismos culturais e intelectuais-sobretudo o francês - na academia brasileira e seu impacto na construção dos elementos mais marcantes do medievalismo brasileiro, os quais ecoam ainda hoje na produção acadêmica e no ensino de história no Brasil.

Se Birro em seu trabalho nos apresenta tal diagnóstico, preciso e necessário para a tomada de consciência das relações coloniais que permeiam a intelectualidade brasileira-em especial aqui o medievalismo, Marcelo S. Berriel nos traz, em sua contribuição, uma proposta de aproximação a partir de uma abordagem decolonial. Em seu trabalho, Berriel faz confluir reflexões sobre as deficiências que o vínculo cego aos modelos euro-referenciados trazem à compreensão dos medievalismos brasileiros, por um lado, e as possibilidades que as propostas decoloniais podem trazer, a partir daquilo que o autor chama de empirismo radical e perspectivismo, ou seja, uma perspectiva que parte essencialmente da experiência brasileira para explicar seus próprios fenômenos, que são ao mesmo tempo próprios e diversos, variando desde a literatura de Suassuna, até o medievalismo religioso presente em movimentos ultra-conservadores. A relação entre medievalismo e religião é, sem dúvida, um campo novo dentro da própria área de estudos do medievalismo. Esse é o sentido do artigo apresentado por Maria Eugenia Bertarelli e Clínio de O. Amaral. Em um instigante trabalho a respeito da missa "Urbi et Orbi" do Papa Francisco 
os autores propõem estratégias para pensar as questões de temporalidade que marcam a prática religiosa do cristianismo e sua constante atualização do passado-também medieval. A partir dessa reflexão, partem então para a análise da missa de Francisco, encarando o conteúdo desta como expressão de uma postura profundamente marcada pelo medievalismo. Ao final de seu trabalho, os autores reforçam a necessidade da ampliação dos estudos do medievalismo em caráter multidisciplinar, assim como propõem, de maneira inovadora, a abordagem das expressões da religiosidade cristã essencialmente como manifestações do medievalismo no mundo contemporâneo. Uma abordagem decolonial acompanha também o trabalho de Otávio L. Vieira Pinto e sua excelente proposta de discussão do colonialismo acadêmico e do medievalismo em torno da história da África ao sul do Saara. A partir desse pressuposto, Vieira Pinto conclui que a ideia de uma África Medieval se concentra sobre o território Ocidental africano não por questões externas, vinculadas à práxis historiográfica (como o acesso a documentação), mas devido, sobretudo, às pressões (políticas) exercidas pelo colonialismo acadêmico, que reconhece ali a emulação de realidades europeias e suas categorias analíticas. Vieira Pinto aponta como a própria noção de uma Idade Média africana acaba por se constituir em uma expressão de “medievalismo de exportação" que atende somente os interesses da academia euro-referenciada e ocidental. Ao se pensar em uma história decolonial e globalizada, é preciso repensar, reforça o autor, as categorias de aproximação aos objetos de análise de modo a promoverem consonância com Berriel-um ambiente de pesquisa que parte da própria realidade estudada para identificar as suas categorias analíticas viáveis.

Essas importantes reflexões de caráter teórico em torno do medievalismo e seu impacto na análise histórica são acompanhadas no presente dossiê por um conjunto de estudos de caso referentes tanto à experiência brasileira, com Elton O. S. Medeiros e Douglas M. X. de Lima, quanto da Europa, com Daniele Gallindo-Gonçalves e Vinicius C. D. de Araujo. O trabalho de Elton Medeiros nos traz importantes contribuições para a intersecção entre medievalismo e educação no contexto brasileiro. Medeiros parte de uma análise de monumentos arquitetônicos da capital paulista que buscam referenciar um (suposto) passado medieval à época de suas construções no âmbito do modernismo. A partir de seus resultados, o autor propõe esses espaços do medievalismo como possíveis fontes para o ensino de história com base nas experiências da sociedade brasileira. De Lima, por outro lado, nos oferece uma análise a partir da noção do lúdico, embasando seu trabalho nas apropriações do passado medieval e suas 
representações em jogos de tabuleiros. $\mathrm{O}$ autor conclui que o medievalismo presente nessa plataforma reforça a construção de um simbolismo atrelado ao imaginário euro-referenciado. Assim, os aspectos do medievalismo se tornam visíveis em novos espaços da cultura de entretenimento, reforçando a sua universalidade enquanto proposta midiática, assim como os problemas que colocam para uma representação da Idade Média em consonância com os avanços da história global e as críticas decoloniais. Mudando o foco para o espaço europeu e para a política, Vinícius de Araújo apresenta nesse dossiê uma análise do medievalismo presente no nacionalismo italiano da Lega Nord e suas influências sobre a política e cultura italianas na contemporaneidade. Daniele Gallindo-Gonçalves, por sua vez, analisa o medievalismo das obras de Otto Rahn e como este influenciou o pensamento nazista em torno da temática do Graal e do catarismo. Ambos os trabalhos transitam em um campo muito fértil da análise do neomedievalismo: a política.

Como já afirmamos, a publicação do presente dossiê recebe um caráter fundacional da área de estudos no cenário brasileiro ao propor novas perspectivas de análise, a discussão de importantes aspectos teóricos, bem como a apresentação de contribuições fundamentais ao campo a partir de uma perspectiva original. Convidamos os leitores da Revista Antíteses a se debruçarem sobre os materiais aqui publicados e buscarem neles a inspiração para o desenvolvimento do campo de estudos do neomedievalismo no Brasil.

\section{Referências}

ALTSCHUL, Nadia R. Politics of temporalization: medievalism and orientalism in nineteenth-century south America. Philadelphia: University of Pennsylvania Press, 2020.

CALIN, William. Leslie Workman: a speech of thanks. In: UTZ, Richard; SHIPPEY Tom (ed.). Medievalism in the modern world: essays in honour of Leslie J. Workman: with the assistance of L. Workman. Turnhout: Brepols, 1998. p. 451-452.

DALBERG-ACTON, John Emerich Edward, Lord. [Epigrafe]. In: FUGELSO, Karl. Defining neomedievalism(s). Cambridge: D. S. Brewer, 2010. (Studies in Medievalism, 19).

MORSEL, Joseph. Le moyen âge vu d'ailleurs. BUCEMA, [Paris], v. 7, p. 1-5, 2003. UTZ, Richard. Speaking of medievalism: an interview with Leslie J. Workman. 
In: UTZ, Richard; SHIPPEY Tom (ed.). Medievalism in the modern world: essays in honour of Leslie J. Workman: with the assistance of L. Workman. Turnhout: Brepols, 1998. p. 433-449.

UTZ, Richard; SHIPPEY, Tom (ed.). Medievalism in the modern world: essays in honour of Leslie J. Workman: with the assistance of L. Workman. Turnhout: Brepols, 1998.

WORKMAN, Leslie. Editorial. Studies in Medievalism, Cambridge, v. 1, n. 1, p. 1-3, 1979.

\section{Notas}

${ }^{1}$ University of Glasgow.

${ }^{2}$ Universidade Estadual de Londrina.

3"medievalism could only begin, not simply when the Middle Ages had ended, whenever that may have been, but when the Middle Ages were perceived to have been something in the past, something it was necessary to revive or desirable to imitate".

4"Two great principles divide the world, and contend for the mastery, antiquity and the middle ages. These are the two civilizations that have preceded us, the two elements of which ours is composed. All political as well as religious questions reduce themselves practically to this. This is the great dualism that runs through our Society".

5“definitive comprehensiveness"; "Classical/medieval divide”.

${ }^{6}$ Pormuito tempo, essa sequência quase implícita tornou desconhecidos os medievalismos pré-românticos.

7“Equal,” “opposite,” “counterweight.” 